\title{
Initial Training of Reading in Mexican Children
}

\author{
Yulia Solovieva, Luis Quintanar \\ Autonomous University of Puebla, Puebla, Mexico
}

\begin{abstract}
In Mexico, such in many other Latin American countries difficulties in reading and comprehension of texts persist up to high school and university levels. This article proposes a new original method for initial training of reading in primary school. The method was designed considering linguistic essential features of Spanish language, including phonological structure and types of relations between sounds and letters. The method is based on creation of reflection of sounds of the language in children. Firstly, the introduction of reading is proposed with the help of symbolic representation of phonological of words. Specific external orientation for each words and letter is taken into account, according to conception of development proposed by Vigotsky. The authors are convinced that the success of the teaching process is determined by conceptual orientation provided by teacher and reflective abilities of children. The method can be used for Spanish-speaking population in different countries.
\end{abstract}

Keywords: training of reading, teaching methods, reading process, primary school education, educational methods, psychological structure of reading, new methods for teaching

\section{Introduction}

Educational system in Mexico, as in many other countries, is facing strong difficulties, especially in teaching of reading in primary school. Strong difficulties in reading and in comprehension of texts persist up to high school and university levels (Olmos Roa, Morales, \& Alvarez, 2002; Olmos Roa, 2002; Chall, 1983). No real substantial proposals exist by now in order to improve or modify the methods of teaching of reading process at school (Fierro \& Martínez, 2001; Nemirovsky, 2006). There are two common methods for introduction of reading are still analytic method and global method.

Analytic method is the most known anti-traditional method all over the world for initial introduction of Indo European languages. The children are taught all letter of correspondent alphabet one by one, sometimes, the order can be changes according to some considerations, for example, the vocals might introduce before consonants. The children learn names of letters as it is in each alphabet. No relation between types of sound, which needs to be pronounced in each particular case, is taken into account. Later one, the child has to learn to join "letters" in words (or in syllables, on modifications). In such situation, children often show strong difficulties in reading aloud, while they are never sure if they manage or not to pronounce the sound correctly. Silent reading is fulfilled practically without any possible comprehension, because the child has no possibility of afferent control of self-articulation of correspondent words (Talizina, 2009; Luria, 1983; Elkonin, 1989). Another variant of analytic method is introduction of "sounds" related to letters. This is done to avoid

Yulia Solovieva, Ph.D., professor of master program in neuropsychology, assessor of Ph.D. program in Educational Sciences of Invero Americana University, Faculty of Psychology, Autonomous University of Puebla.

Luis Quintanar, Ph.D., director and professor of master program in neuropsychology, president of Latin American Society of Neuropsychology (SLAN), Faculty of Psychology, Autonomous University of Puebla. 
presentation of "mane of letters" of the alphabet. Such modification pretends to teach "sounds" of correspondent language. The big problem in this situation is that the "sounds" do not exist in language as independent unites. The sounds could be discovered and identified only as real phonetic and phonemic components of words (Leontiev, 2001). Another serious problem is that no direct relation between letter and sound exists in none of European languages. Let us give only one example of letter "g" in Spanish. If the next letter is vocal "a", "o", and " $u$ ", this letter represents voiced consonant. If the next letter is vocal "e" and "i", the same letter corresponds to unvoiced consonant (Solovieva \& Quintanar, 2011). The similar situation can be found in other languages (Elkonin, 1995). In this case, Spanish language should not be considered as "transparent" language. According to our opinion, it is not correct to make distinction between "transparent "and "non-transparent languages". Instead of this, it is necessary to study the real structure and the system of relations between letters and sounds in each particular language.

As an alternative to analytic method, global method was proposed by some researchers in the field of education and child psychology in Mexico (Ferreiro \& Teberosky, 2005; Ferreiro, 2007; Ferreiro \& Gómez Palacio, 2010). From the first point of view, it looks as a good alternative. Instead of presentation of isolates letters (or sounds), the entire words are presented to the child. As it is well known, global method consists in recognition of complete visual image of words which the child has to read. No specific consideration of components of the words (letters or sounds) takes part in this method. No reflection is provided by teachers during usage of global method. Children have to "guess" or to evoke by memorizing the sound structure of each word they see. If they fail, they use any choice of "close" word according to visual configuration of letters. The teachers often, while using this method, provoke the training only of mechanic memory as they put the card with written word on some objects in the classroom. The problem is that it is impossible to put the same card neither for case of verbs and adjectives nor for abstract concepts. The children can be able to learn first 100 words, but later the one mix up all of them. In higher grades, after usage of this method, children show absence of comprehension of texts.

Do we have any alternative for initial training of reading for Spanish language?

From psychological point of view, the period of school learning should be based on gradual formation of concepts by steps (Galperin, 2011; Talizina, 2000, 2009) instead of traditional training of separate habits and abilities of pupils. The basic activity of this age is the directed school learning divided between two participants: teacher and pupil. The teacher has to be theoretically and methodologically prepared to fulfill such activity. According to Vigotsky's psychological conception and activity theory (Davidov, 1996; 2000), only this type of activity guarantees the establishment of such neo-formations as complete self-voluntary regulation and self-reflection as important characteristics of personality. Another important achievement of primary school should be the capacity of theoretical thinking instead of empirical thinking predominant in pre-school age (Talizina, 1984, 2000; Obukhova, 2006; Davidov, 2000). Obviously, the success of a child in acquisition of reading depends on the level of previous preparation for school learning (Salmina, 2010). Nevertheless, we also consider that traditional methods of school teaching are very far at this moment to solve the problem of learning disabilities and low success in school learning including poor reading and language comprehension. According to pedagogical psychology developed on the bases of cultural-historical conception of Vigotsky (1995; 1996), it is possible to create more productive methods of education. Since proposals of Talizina $(2002 ; 2009)$, such methods could be called "invariant methods" if they satisfy the following theoretical methodological principles of modern activity theory of learning process: 
(1) Cultural and historical nature of child's abilities;

(2) Straight relation between pedagogical method (cultural sphere) and child's learning abilities (individual sphere);

(3) Learning process is a specific kind of directed activity divided between teacher and pupil;

(4) Learning activity has its own structure: motive, objective, orientation base of action, operations, and result;

(5) Construction of orientation base of action from external level with posterior gradual interiorization as essential part of the actions;

(6) Reconsideration of school objects (reading in this case) as a system of concepts and actions instead of empiric or chaotic organization of learning process;

(7) Gradual formation of these concepts and actions starting from the most general in the direction to the most particular;

(8) Usage of Vigotsky's concept of the zone of proximate development in real process of formation of concepts and actions according to the level of presentation of action and of joint elaboration of orientation base of action between teacher and pupil (Solovieva, 2004; Solovieva \& Quintanar, 2004).

The objective of our study is to show the possibilities of elaboration and application of such method for initial training of reading for Spanish language. The method was created on the bases of the theory of historic and cultural development and activity theory using the former proposal of Elkonin (1989) elaborated for Russian language. Our method for formation of reading was modified in comparison with original proposal for Russian language (Solovieva \& Quintanar, 2005; 2011). Our modifications are related to:

(1) Linguistic features of sounds in Spanish language;

(2) Types of co-relation between verbal sounds and letters used in Spanish language;

(3) Necessity of special work on images and graphic activity with children of first year of school education;

(4) Necessity of stressing of order of sounds on oral level and of letters on written level.

The method is being applied to Mexican children in primary school during the first year for the program of Spanish language. The method was used within experimental research programs provided by master program in neuropsychology for post-graduate students at Faculty of Psychology of Puebla Autonomous University (Solovieva \& Quintanar, 2008; Solovieva, Pelayo, \& Quintanar, 2011). By now, the method is used at private school college "Kepler" in the city of Puebla and is guided by the authors of this article.

\section{Method}

In this presentation, we report the qualitative pedagogical experience and some of most important results of application of invariant method for reading formation to different groups of children from the city of Puebla:

(1) A group of normal children of urban private school (25 children) who assisted first grade of primary school;

(2) Twenty children with different kinds of learning disabilities of pre-school and school age (between the age of five, one, and eight years).

All children were submitted to assessment before and after working with the method. Normal children were submitted to psychological assessment for preparation to school and children with learning disabilities to neuropsychological assessment in order to establish the reason of the difficulties from the point of view of brain 
functional mechanisms. Both kinds of assessment which were individual and required of one hour session in case of normal children and four hours in case of children with difficulties. The results were submitted to qualitative and quantitative analyses.

The method for initial introduction of reading was applied to all children. In the case of normal children, the method was used during the whole school year by the teacher who was trained previously. In the case of children with difficulties, the method was used as a part of individual programme for neuropsychological correction. In each case, specific modifications of the procedure of applied of the method were made according to the necessities and possibilities of the child and the type of difficulties (Solovieva, 2008; Quintanar \& Cols, 2009). The duration of such correction varies at 6-8 months of individual Sessions $2-3$ times per week.

\section{Instruments for Assessment}

The assessment was accomplished with the help of the scheme for evaluation of the level of preparation for school and scheme for child neuropsychological assessment (Solovieva \& Quintanar, 2009a). The schemes have been elaborated according to conception of basic activity and neo-formations of pre-school age and Luria's theory of brain mechanisms (Talizina, Solovieva, \& Quintnar, 2010; Akhutina, 2002; Akhutina \& Pilayeva, 2012). Assessment included tasks for repetition and reading of sounds, words, and sentences (Quintanar \& Solovieva, 2012).

\section{Method for Initial Introduction of Reading}

The method for training of reading in Spanish on initial stage of learning included the following stages:

(1) Oral phonetic analysis of words in Spanish: Identification of stressed and non-stressed vowel sounds;

(2) Phonetic analysis with the help of external materialized action: (a) Introduction of materialized scheme of verbal sound in each particular word; (b) Materialization of vowel sounds; (c) Materialization of consonant sounds; (d) Materialization of stressed vowel sounds; (e) Materialization of soft sound " $\tilde{n}$ " and hard sound " $n$ " ; and (f) Materialization of long sound "rr" and short sound " $r$ ";

(3) Phonetic analysis with the help of external graphic action: (a) Graphic representation of the scheme of the sound of each word; (b) Graphic representation of vowel sounds; (c) Graphic representation of consonant sounds; (d) Graphic representation of soft sound "ñ" and hard sound "n" ; (e) Graphic representation long sound "rr" and short sound " $r$ ";

(4) Introduction of letters with the help of materialized external action: (a) Introduction of letters which correspond to vowel sounds; and (b) Introduction of letters which correspond to consonant sounds (according to the order of rules for correlation between setter and sound of Spanish language);

(5) Introduction of the action of writing and reading of letters: (a) Writing and reading of letters which determine vowels of Spanish language; and (b) Writing and reading of letters which determine consonants of Spanish language;

(6) Independent reading and writing of words and sentences.

During the work with the method, the adult (teacher in group or neuropsychologist in correction individual session) directed all executions of the children. The external scheme of the word served as orientation base of action of phonetic analysis of the words. Initially, the teacher presented known words, later on, new words were presented gradually to the children.

At the first stage, the child pronounced the word with help of an adult and tried to fill the presence of different kind of sound in the words. At the stage of materialized action, the child has to learn not only to fill 
the existence of sounds, but also to determine the amount of sounds in each word and to represent it with the help of the scheme. The materialized scheme could be understood as external psychological instrument in terms of Vigotsky (Solovieva \& Quintanar, 2009b). It helps children to represent internal structure of an abstract object (word) by means of symbolic operation (Salmina, 1981; 1984). In this case, it is possible to use specific pedagogic and psychological methods in order to facilitate mental representation of abstract verbal objects. According to Leontiev (2009), the assimilation of an object may only take place after the child apprehends to realize an action with include correspondent object.

Example of materialized scheme of the word "pato" (duck). In Spanish, this word consists of four sounds (see Figure 1). The scheme represents the pronunciation of the word in Spanish without any usage of letters.

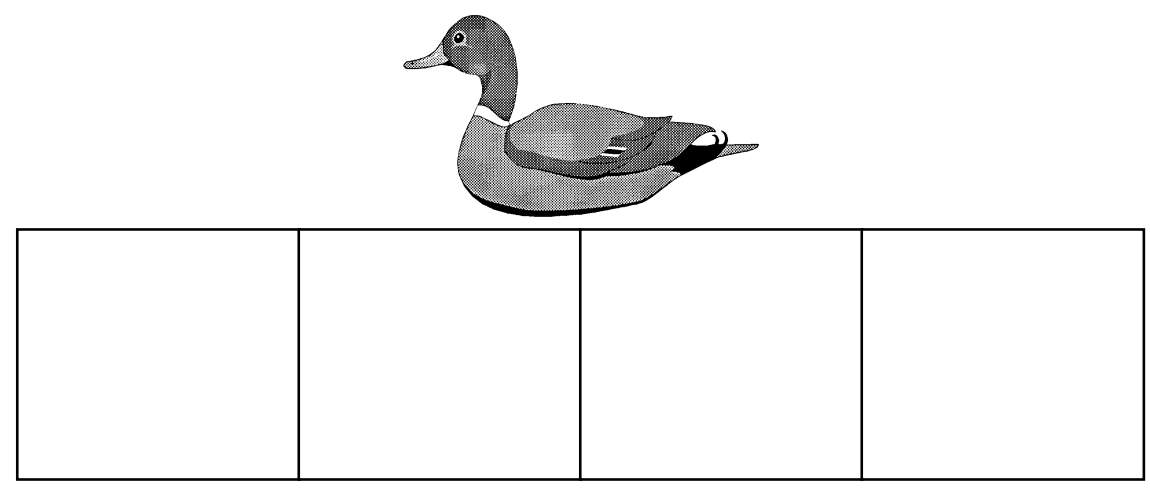

Figure 1. Materialized scheme of the word "pato".

Later on, the white circles are placed on the scheme. At this stage, the child does not know types of sound neither names of letters, but he/she learns to perceive the order of the sounds and the whole phonetic structure of every word (see Figure 2). At this stage, the children learn to listen to each sound in structure of the word: vowels and consonants together.

Example:

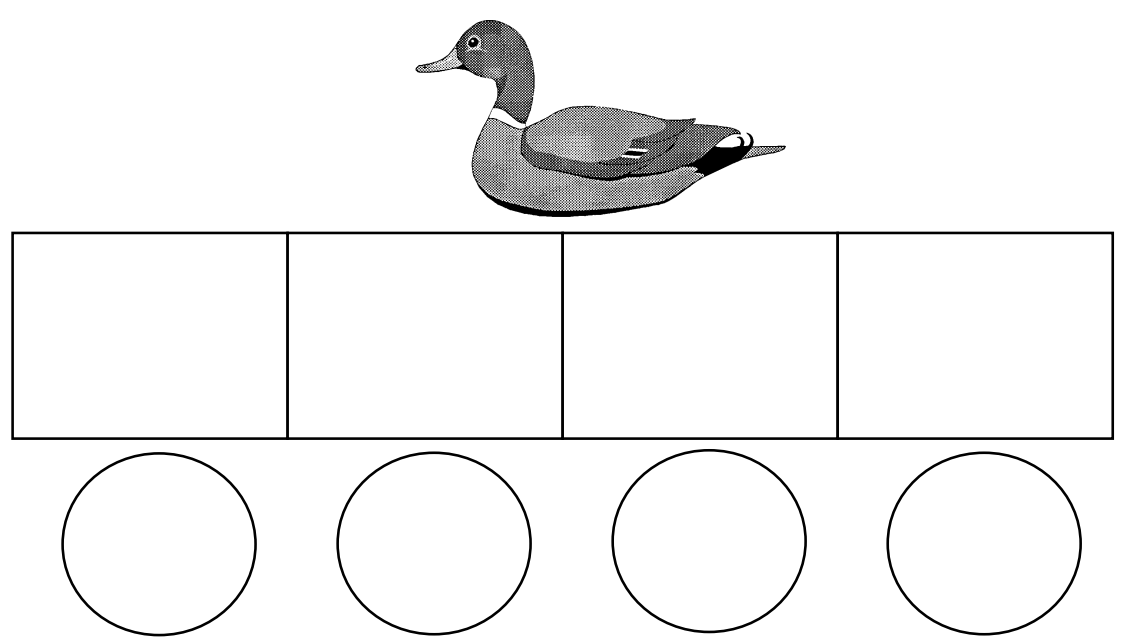

Figure 2. Materialized scheme of the word "pato" with circles for representation of each sound.

Gradually, with the help of orientation of an adult, the child learns to differentiate the types of sounds: vowels and consonants. The child has to substitute the white circle by red (for vowels) or green circle (for consonants) in the scheme of the word. In this scheme, the circles of different colors are used. In this case, the 
first two and the forth circles should be red and the third and the last one should be red color.

Example: "fresa" (strawberry). This word consists of five sounds (see Figure 3).

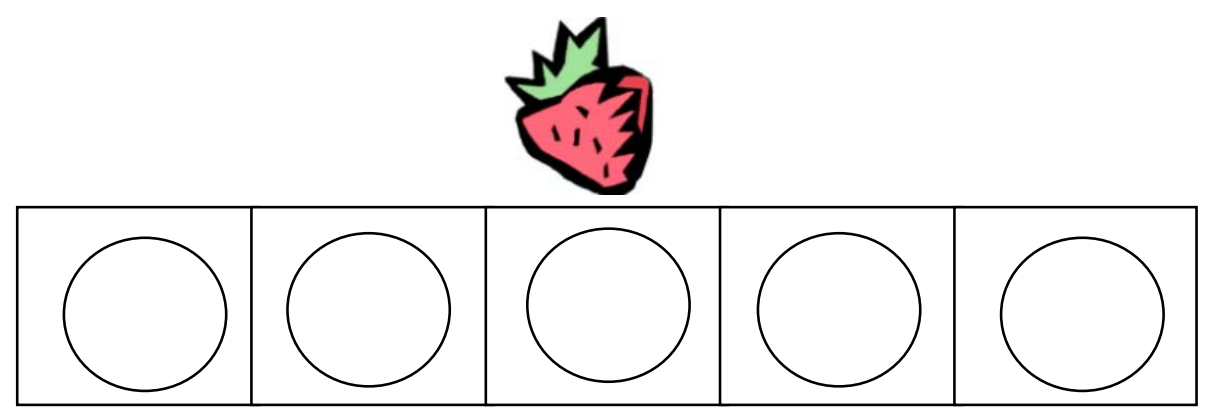

Figure 3. Materialized scheme of the word "fresa".

The child also learns to discriminate stressed and non-stressed vowels in the words. The special external "stress" is used in the schemes.

Example: "elefante" (elephant). The Spanish word has eight sounds (see Figure 4). In this scheme, also differentiation by colors should be used: red color for vowels and green color for consonants.
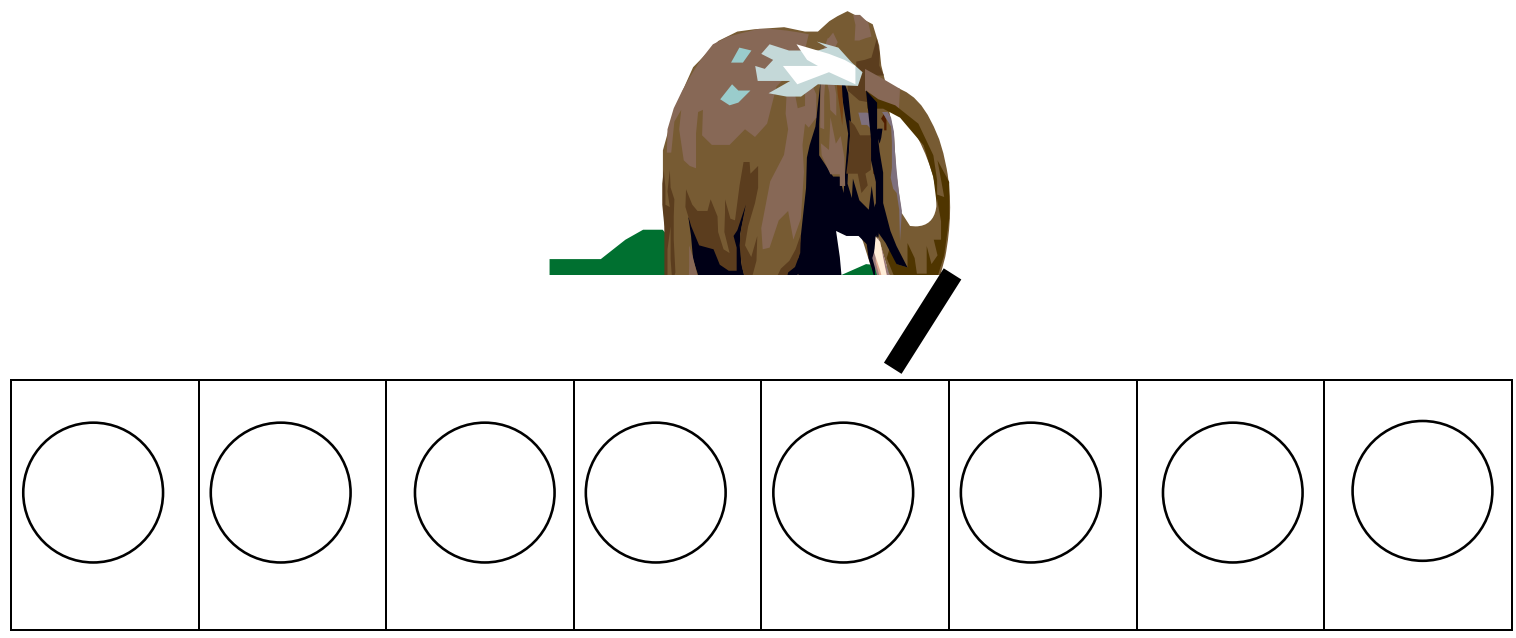

Figure 4. Materialized scheme of the word "elefante".

At the next stage, the child has to fill and to determine the "soft" voiced sound " $\tilde{n}$ " in comparison with "hard" voiced consonant sound " $n$ ". The teacher has to give examples of the words with these sounds and to stress the difference in their meaning. These differences are marked in external schemes of the words.

Example: "mono" (monkey) (see Figure 5).

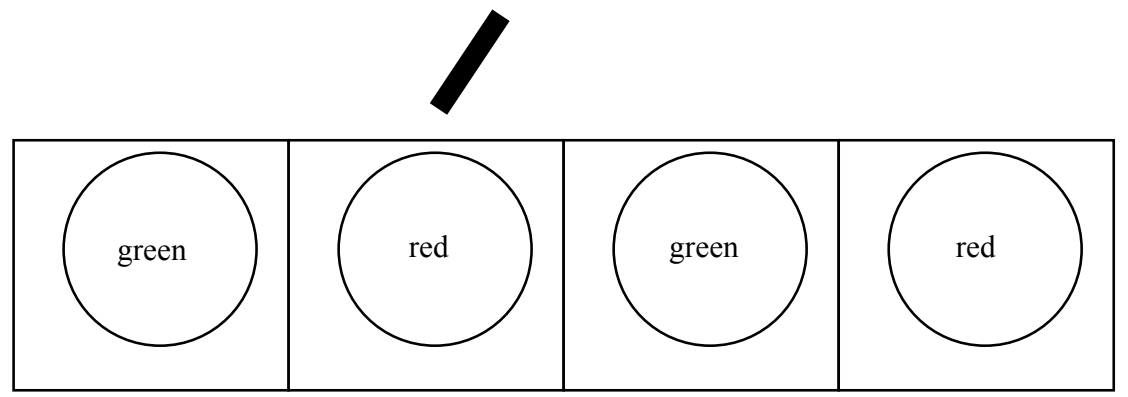

Figure 5. Materialized scheme of the word "mono" with representation of stressed vowel. 
Example: "moño" (bow) (see Figure 6).

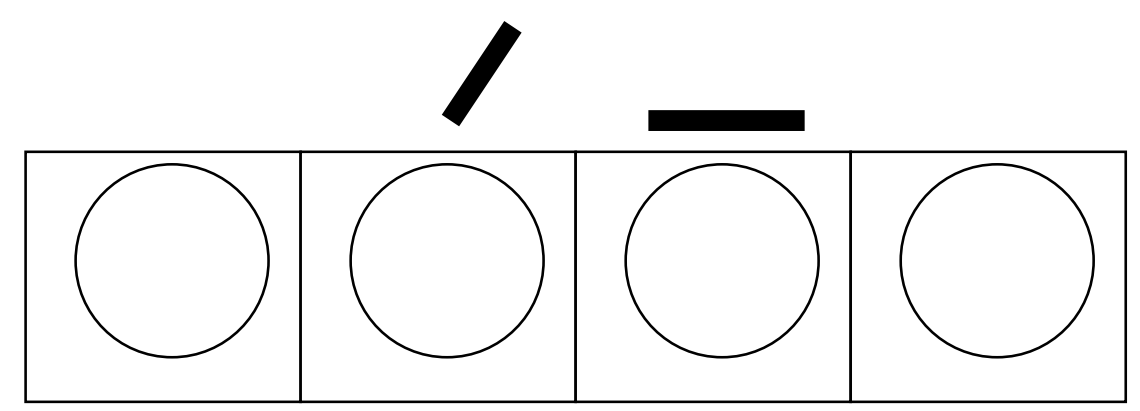

Figure 6. Materialized scheme of the word "moño" with representation of stressed vowel.

Another important phonematic characteristic in Spanish language is differentiation of long consonant sound "rr" and short consonant sound "r". The teacher or therapist gives the examples of such words and the child learns to differentiate these sounds by marking it with two little green circles or one green circle as for any consonant sound.

Example: "perra” (feminine noun “dog”) (see Figure 7).

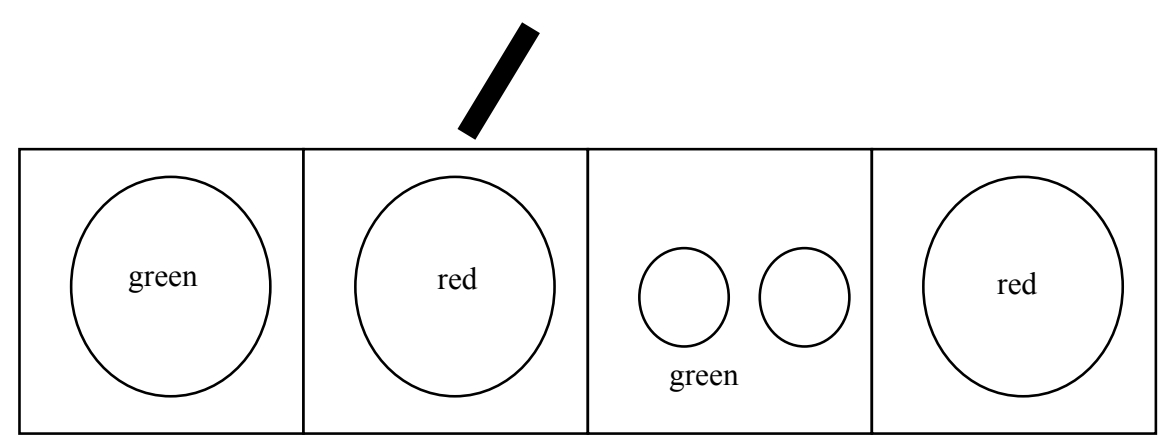

Figure 7. Materialized scheme of the word "perra" with representation of long consonant "rr".

Example: "pera" (pear). In order to differentiate these two words in Spanish, it is necessary to perceive the difference between long and short sound. Children are confused in this situation very often and commit mistakes in their writing. That is why we propose special training for perception of these consonants (see Figure 8).

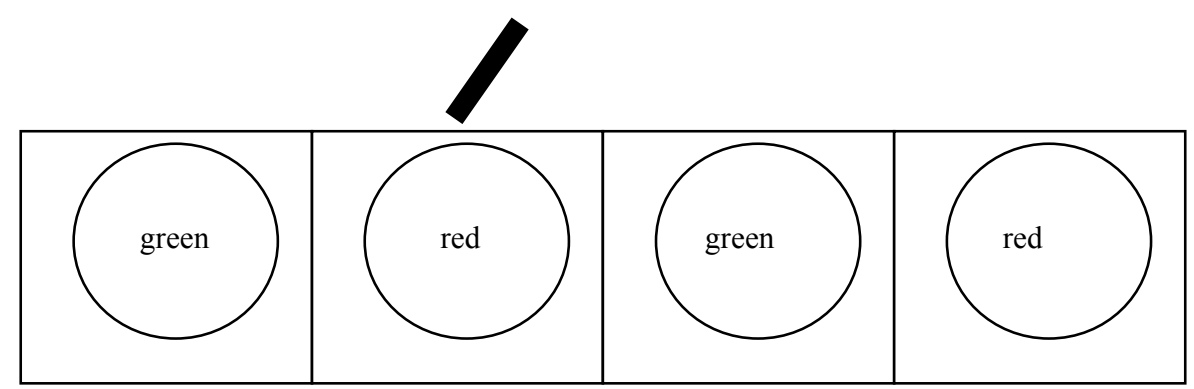

Figure 8. Materialized scheme of the word "pera" with representation of short consonant "r".

On graphic stage, the child fulfils the same kind of tasks. The difference is that instead of elaboration of material schemes, the child has to draw the schemes and the circles (see Figures 9 and 10).

Example: "oso" (bear). In this example, the child draws only white circles to represent the sounds of the word. 


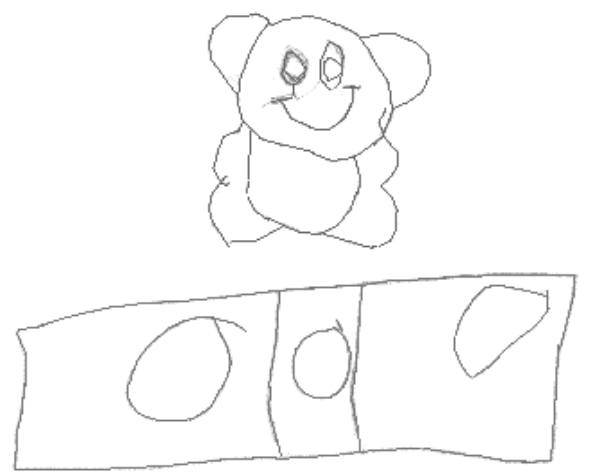

Figure 9. The execution of the scheme for the word "oso" by six years old child.

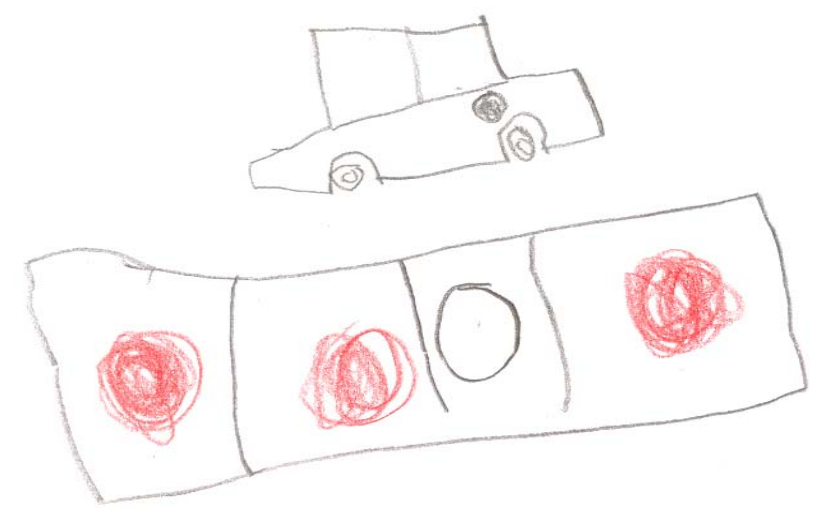

Figure 10. The execution of the scheme for the word "auto" by six years old child.

Example: "auto" (car). In this original execution of the child, the first two and the last circles are red (vowels) and while the third circle is white (consonant). On this stage, the child represents only vowels with color.

Letters are gradually introduced on the next stage. First, we introduce letters for vowels and later letters for consonants.

Example: "sol" (sun) (see Figure 11). In this example, the child represents vowels (red colour) and consonants (green colour).

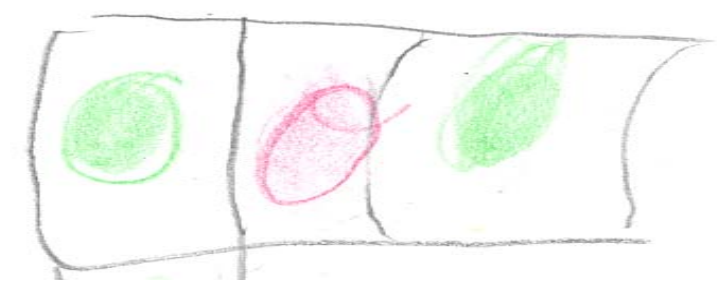

Figure 11. The execution of the scheme for the word "sol" by six years old child. 
Finally, the child learns to read and write the words with all conventional letter of Spanish alphabet. The scheme is eliminated on the last stage of the work with the method.

Example: written word "perro" (dog) (see Figure 12).

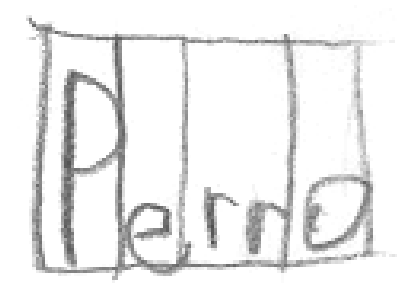

Figure 12. Writing of the word with the help of the scheme.

Example: "baño" (bathroom) (see Figure 13).

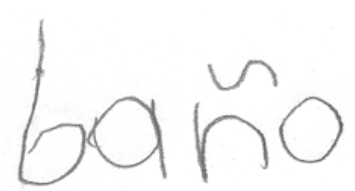

Figure 13. Independent writing of the word.

At the final stage of the method, children are able to read and write practically all words, sentences, and texts in books according to their age. All external schemes are suspended at the end of application. Children never "guess" the words, they always read. Children never read by syllables, they read entire words. If they do not understand the meaning of some words, they ask their teacher.

\section{Results and Discussion}

The results obtained as the consequence of the usage of the method show special achievements in writing, reading, and general linguistic abilities after application of method during a school year or as a part of correction sessions with children who have difficulties in their development. In case of group application of the method, it was possible to use other kind of creative activities with children, such as play "guess the word", "change the word by changing 1 (2, 3, etc.) sound", "collective analysis of long complex non-frequent words", and many others. We find it useful to divide the achievements into theoretical conceptual knowledge about language, practical help for reading and writing process at school.

All children have formed the following theoretical important knowledge about the language:

(1) Sound and letter is not the same and letter is not the name of the sound. There is a level of sound in our words and the letters which are the symbols which represent sound and their combinations;

(2) There are two main kinds of sound: vowels and consonants. Sounds may differ according to other characteristics (long-short and soft-hard);

(3) The words can consist of different quantity of sound and also of vowels and consonants;

(4) Sounds have special place and order in the words;

(5) It is possible to change the words (meaning) by changing the sounds.

Important achievements were noticed in reading and writing of all children. Positive characteristics of the reading process were the following:

(1) The children never read by syllables, but by whole words in all occasions from the very beginning; 
(2) The children never committed mistakes of confusion between letters, omission of sounds, or sound anticipation in the words;

(3) The children were able to read at once sentences and short text corresponding to their age with good comprehension at the end of the work with the method.

In the process of writing the positive results were:

(1) The children were able to separate accurately one word from another in their writing;

(2) No letter in the words was wrongly separated by children;

(3) A considerable number of common orthographic mistakes in Spanish language were prevented with the help of the method (confusion between " $n$ " and " $\tilde{n}$ ", confusion between " $r$ " and "rr", wrong usage of special cases with letters "g", "c", "k", "q", and others). The work on introduction of specific rules for sound-letter correlation forms an important part of the method (this part of the method was not included in the present report).

The teacher who worked with the children expressed big differences between possibilities of this group and other children who were learning by traditional (analytic or global) training of reading. The children of normal group showed no difficulties in final psychological assessment. All of them were successful in reading and writing according to the program of Mexican Ministry of Education for the first school year. The group of children with specific difficulties and learning difficulties showed significant progress determined by final neuropsychological assessment.

We would like to stress that the introduction of new invariant methods elaborated according to theoretical and methodological proposals of cultural-historic psychology and activity theory could be very useful and productive not only as a method of education and correction of learning disabilities, but also as a method of prevention of many other kinds of difficulties, mistakes, and confusion in future steps of education and in acquisition of second or third (etc.) language, which is especially important in modern global communication. We are sure that proposed method could help on the way of improving situation with school success not only in Mexico, but also in all contexts where Spanish is taught. United States might be one of possibilities for implementation of the method since that a great percentage of population speak Spanish or are of Latin American background. New methods for improvement of educational level and state of emotional health of this population should be introduced.

\section{Conclusion}

The proposed method for initial introduction for reading showed positive results in normal children and in children with learning difficulties.

Such positive results are related to concepts acquisition (intellectual development) and practical usage of reading and writing correspondent to the age of the children.

In case of difficulties, it is necessary to base program of correction and modifications of the method in correspondence with accurate diagnostic.

The theoretical and methodological bases of the method open the possibility of creation of such methods for other languages different to Spanish and their broad usage in pedagogical and psychological day-to-day practice.

It is necessary to create other invariant methods for other steps of language acquisition, for example, for initial introduction of grammar in primary school. 
Frequently, learning disabilities and low success school learning are related to the absence of adequate pedagogical methods.

\section{References}

Akhutina, T. V. (2002). Assessment and correction of writing. Spanish Journal of Neuropsychology, 4(2-3), 236-261.

Akhutina, T. V., \& Pilayeva, N. M. (2012). Overcoming learning disabilities: A Vigotskian-Lurian neuropsychological approach. Cambridge: Cambridge University Press.

Chall, J. (1983). Stages of reading development. New York, McCraw-Mill.

Davidov, V. V. (1996). The theory of teaching which leads to development. Moscow: INTER.

Davidov, V. V. (2000). Types of generalization and teaching. Moscow: Russian Pedagogical Society.

Elkonin, D. B. (1989). Sellected works. Moscow: Pedagogy.

Elkonin, D. B. (1995). Psychological development in childhood. Moscow: Academy of Pedagogical and Social Sciences.

Elkonin, D. B. (1999). Psychology of play. Moscow: Vlados.

Ferreiro, E. (2007). The children of iliteracy: Proposals for school alphabetization in Latin America. Mexico: Century XXI.

Ferreiro, E., \& Gómez Palacio, M. (2010). New perspectives for process of reading and writing. Mexico: Century XXI.

Ferreiro, E., \& Teberosky, A. (2005). The systems of writing in child development. Mexico: Century XXI.

Fierro Evans, M. C., \& Martínez Parente, Z. R. (2001). How to teach reading by workshop for prescholars? Mexico: Mexican Foundation for Reading.

Galperin, P. Ya. (2011). Formation of concepts and mental actions. In L. Quintanar, \& Yu. Solovieva (Eds.), Psychological functions during child development (pp. 80-90). Mexico: Trillas.

Leontiev, A. A. (2001). Language and verbal activity in general psychology and pedagogy. Moscow: Russian Academy for Education.

Leontiev, A. N. (2009). Psychological bases of child development and teaching. Moscow: Sense.

Luria, A. R. (1983). The development of reading in the child. In M. Martlew (Ed.), The psychology of written language: Developmental and educational perspectives (pp. 237-277). Chichister, UK: Wiley.

Nemirovsky, M. (2006). About teaching of written language and related themes. Barcelona: Paidos.

Obukhova, L.F. (2006). Psychoogy of development. Moscow: Superior Education.

Olmos Roa, A. (2002). Educational application of socio-cultural theory. Mexico: Faculty of Superior Studies Zaragoza.

Olmos Roa, A., Morales, I. O., \& Alvarez Sánchez, L. (2002). Proposal of collaborative culture: Fundamental ideas in high education. In A. Olmos Roa (Ed.), Educational application of socio-cultural theory. Mexico: Faculty of Superior Studies Zaragoza.

Quintanar, L., \& Solovieva, Yu. (2012). Neuropsychological assessment in school age. Mexico: Autonomous University of Puebla.

Quintanar, L., Solovieva, Yu., Lázaro, E., Bonilla, R., Mejía, L., \& Eslava, J. (2009). Difficulties in the process of reading and writing. Mexico: Trillas.

Salmina, N. G. (1981). Types and functions of materialization in teaching. Moscow: Moscow State University.

Salmina, N. G. (1984). Sing and symbol in education. Moscow: Moscow State University.

Salmina, N. G. (2010). Indicators of preparation for school learning in children. In Yu. Solovieva, \& L. Quintanar (2010). Anthology of psychological development in preschool age. Mexico: Trillas.

Solovieva, Yu. (2004). Intellectual development and its assessment: Historical and cultural conception. Mexico: Autonomous University of Puebla.

Solovieva, Yu. (2008). A method for formation of reading in children with dificulties. In L. Quintanar, Yu. Solovieva, E. Lázaro, R. Bonilla, L. Melía, \& J. Eslava-Cobos (Eds.), Difficulties in the process of writting and reading. Valladolid, Spain: Editory of Infancy.

Solovieva, Yu., \& Quintanar, L. (2004). Usage of the zone of proximate development during assessment of development of intellectual activity. In S. Castañeda (Ed.), Education, learning and cognition: Theory and practice. Mexico: Modern Manual.

Solovieva, Yu., \& Quintanar, L. (2005). Method for reading formation. Mexico: Autonomous University of Puebla.

Solovieva, Yu., \& Quintanar, L. (2008). Child neuropsychological education. Mexico: Trillas.

Solovieva, Yu., \& Quintanar, L. (2009a). Brief neuropsychological assessment for children. Mexico: Autonomous University of Puebla. 
Solovieva, Yu., \& Quintanar, L. (2009b). Introduction of reading from historical and cultural conception. In E. A. Escotto, M. Pérez, \& M. A. Villa (Eds.), Development and disturbances of language, neuropsychology and genetic of intelligence. Mexico: Nacional Autonomous University of Mexico.

Solovieva, Yu., \& Quintanar, L. (2011). Teaching of reading: Practical method for reading formation. Mexico: Trillas.

Solovieva, Yu., Pelayo, H., \& Quintanar, L. (2011). Method for formation of reading designed according to L. S. Vigotsky proposals: Between teachers. Journal of National Pedagogical University, 11(38), 58-65.

Talizina, N. F. (1984). Direction of the process of assimilation of knowledge. Moscow: Moscow State University.

Talizina, N. F. (2000). Pedagogical psychology. Mexico: Autonomous University of San Luis Potosí.

Talizina, N. F. (2002). Practical work for pedagogical psychology. Moscow: Academy.

Talizina, N. F. (2009). Activity theory applied for teaching. Mexico: Autonomous University of Puebla.

Talizina, N. F., Solovieva, Yu., \& Quintanar, L. (2010). Activity theory approximation in psychology and its relation with historical and cultural conception. Buenos Aires: Educational News.

Vigotsky, L. S. (1995). Selected works: Tomo 3. Madrid, Visor.

Vigotsky, L. S. (1996). Selected works: Tomo 4. Madrid, Visor. 